\title{
ANÁLISE DAS PROPRIEDADES DO CONCRETO COM VARIAÇÃO DOS TIPOS DE CIMENTO
}

\section{ARTIGO DE REVISÃO}

MORAIS, Brunno Borges ${ }^{1}$

SILVA, Lettycia Pinheiro da ${ }^{2}$

LIMA, Lívia Ramos ${ }^{3}$

INÁCIO, Raquel Ferreira ${ }^{4}$

SANTOS, Rivaldo Silva ${ }^{5}$

PRADO, Romenique Almeida ${ }^{6}$

Welliton Igor Carvalho de ${ }^{7}$

MORAIS, Brunno Borges. Et al. Análise das propriedades do concreto com variação dos tipos de cimento. Revista Científica Multidisciplinar Núcleo do Conhecimento. Ano 05, Ed. 05, Vol. 01, pp. 05-25. Maio de 2020. ISSN: 2448-0959, Link de acesso: https://www.nucleodoconhecimento.com.br/engenharia-civil/tipos-decimento

\footnotetext{
${ }^{1}$ Graduando em Engenharia Civil.

2 Graduanda em Engenharia Civil.

${ }^{3}$ Graduanda em Engenharia Civil.

${ }^{4}$ Graduanda em Engenharia Civil.

${ }^{5}$ Graduando em Engenharia Civil.

${ }^{6}$ Graduando em Engenharia Civil.

${ }^{7}$ Graduando em Engenharia Civil.
} 


\section{RESUMO}

O presente trabalho apresenta uma análise qualitativa dos tipos de cimento que estão a disposição no setor construtivo e são comercializadas em diferentes regiões do país, buscando investigar e comparar parâmetros de grande importância para a construção civil. Foi realizada uma pesquisa bibliográfica a respeito dos temas pertinentes ao assunto, tais como concreto, composição do concreto, origem e fabricação do cimento etc. À luz dessa revisão, foi elaborado o estado da arte do tema, abordando várias perspectivas de diferentes autores a respeito da variabilidade das propriedades do concreto, proporcionada pelo tipo de cimento. Com isso, foi possível concluir que este é um campo de pesquisa bastante vasto e importante no ponto de vista da ciência e tecnologia dos materiais, ao passo de que é visível a variação dos resultados de concretos obtidos com diferentes tipos de cimento, o que propicia novos estudos, podendo variar e analisar outros parâmetros importantes como módulo de finura, resistência a outros esforços, entre outros.

Palavras-chave: Parâmetros, cimento, ciência, tecnologia dos materiais.

\section{INTRODUÇÃO}

O concreto é o material de construção mais difundido pelo mundo, sendo o resultado da mistura de cimento, agregados e água, que, após passar pelo processo de endurecimento e cura, apresenta alta resistência mecânica, propriedade essa que é explorada por engenheiros e arquitetos (HELENE; ANDRADE, 2007). Assim, o estudo sobre sua composição, dosagem, testes de resistências e a qualidade dos materiais utilizados apresenta elevado grau de importância para os profissionais do campo da construção civil, assim como para comunidade científica, estudantes e pesquisadores, empreendedores e demais profissionais da área.

O cimento mistura pulverulenta, seca e com baixíssimo teor de umidade, é resultante de uma série de processos que envolvem uma composição dosada e controlada de minérios, sendo protagonista na fabricação de concretos e argamassas (GALHARDO, 2014). O material é fabricado ao redor do mundo de modo similar com relação aos 
minérios que o compõem e as fases de produção (VARELA; VIEIRA, 2005). composto higroscópico, quando em contato com a água, tende a formar uma pasta viscosa e densa, esta reação química libera calor de hidratação tendendo ao ganho de resistência principalmente ao esforço de compressão.

Com intuito de explorar as particularidades e o desempenho dos cimentos disponíveis no mercado, levando em consideração que com a regionalidade existem costumes e tendências onde alguns produtos acabam tendo maior recorrência e popularidade, foi visto a necessidade de verificação dos atributos desses materiais sendo de grande importância a avaliação se há, ou não, diferença ou variação considerável das suas propriedades entre tipos distintos de cimento.

Entretanto, é sabido que existem diferenças dos valores absolutos das resistências obtidas, por exemplo, em função dos processos que envolvem dosagem e os processos de lançamento, adensamento e cura do concreto. A composição e o processo de fabricação são normatizados pela ABNT NBR 16697 (2018), atualizada e alinhada com alguns conceitos da comunidade internacional, sendo presumível que todo o processo e requisitos de fabricação sejam semelhantes no Brasil onde a norma é válida. Assim, por meio de estudos científicos e revisão bibliográfica é visível a necessidade de averiguar se realmente há influência dos tipos de cimento no resultado do concreto.

\section{CONCRETO}

Segundo Pedroso (2009), atualmente, o concreto é o material construtivo de maior uso ao redor do mundo, estando presente em: casas de alvenaria estrutural, pontes, barragens, edifícios em concreto armado e de estruturas mistas, usina hidrelétricas, torres, obras de saneamento, dentre outras. O consumo anual chega a 1,9 toneladas ao ano por habitante totalizando aproximadamente 11 bilhões de metros cúbicos, ficando atrás apenas para o consumo de água. No Brasil, com base em dados de concretos dosados em centrais, totalizam-se 30 milhões de metros cúbicos anuais (PEDROSO, 2009). 
Segundo a ABNT NBR 12655 (2015), no item 3.1.1, concreto é definido como:

Concreto de cimento Portland: Material formado pela mistura homogênea de cimento, agregados miúdo e graúdo e água, com ou sem a incorporação de componentes minoritários (aditivos químicos, metacaulim ou sílica ativa), que desenvolve suas propriedades pelo endurecimento da pasta de cimento (cimento e água). (NBR 12655, 2015).

Sendo assim, o concreto é o resultado da mistura de cimento, agregados e água, que após o endurecimento resulta numa pedra artificial com propriedades mecânicas capazes de moldar a inventividade construtiva (PEDROSO, 2009).

Ainda que o concreto seja reconhecido, dentre muitas de suas características, por ser um elemento que apresenta alta rigidez e dureza (NEVILLE, 2016), é interessante pontuar que as propriedades do concreto são estabelecidas, em boa parte, durante sua fabricação, momento em que a mistura do cimento, água e agregados apresenta viscosidade e fluidez (SOBRAL 2000).

A fluidez do concreto é um fator determinante na resistência do concreto. A relação água/cimento no traço, além de influenciar na resistência e trabalhabilidade do concreto, expressa o quanto é fluido o concreto, portanto quanto maior essa relação mais fluida é a pasta (HELENE; ANDRADE, 2007).

Conforme Helene e Andrade (2007, p. 920), "a fluidez da pasta, constituída de cimento e água, dependerá, essencialmente, da distribuição granulométrica do cimento e da quantidade de água adicionada, que é expressa pela relação água/cimento." Resumidamente, a fluidez é uma característica importante a ser observada, e tem relação direta com a granulometria do cimento, para isso a NBR 11579 (2012) estabelece critérios para a determinação da finura do cimento Portland.

Com o crescimento do setor construtivo, é indispensável a busca pela qualidade dos materiais que são utilizados. No que diz respeito ao concreto, se faz necessário o estudo e controle das suas propriedades em seu estado fresco, para a execução, e 
em seu estado endurecido, que está relacionado à vida útil da construção (SOBRAL, 2000).

\subsection{RESISTÊNCIA À COMPRESSÃO}

A resistência à compressão do concreto possui um valor significativo, logo essa resistência é de vital importância no dimensionamento de estruturas e na qualidade do concreto. Segundo Vieira (2007), é importante a realização do ensaio de compressão axial do concreto para que se obtenha um valor característico único para um determinado lote de corpos de provas, sendo esse valor comparado ao valor requerido em projeto.

As normas NBR 5738 (2015) - Concreto - Procedimento para moldagem e cura de corpos de prova - e NBR 5739 (2016) - Concreto - Ensaio de compressão em corpos de prova cilíndricos - regem a realização do ensaio de compressão e da moldagem dos corpos de prova de concreto. Com os valores obtidos para as resistências, $F c$, é traçado um gráfico em função da quantidade de corpos de provas ensaiados. Exemplo do gráfico é apresentado na figura 1.

Figura 1: Gráfico valores de resistência VS quantidade de corpos de prova

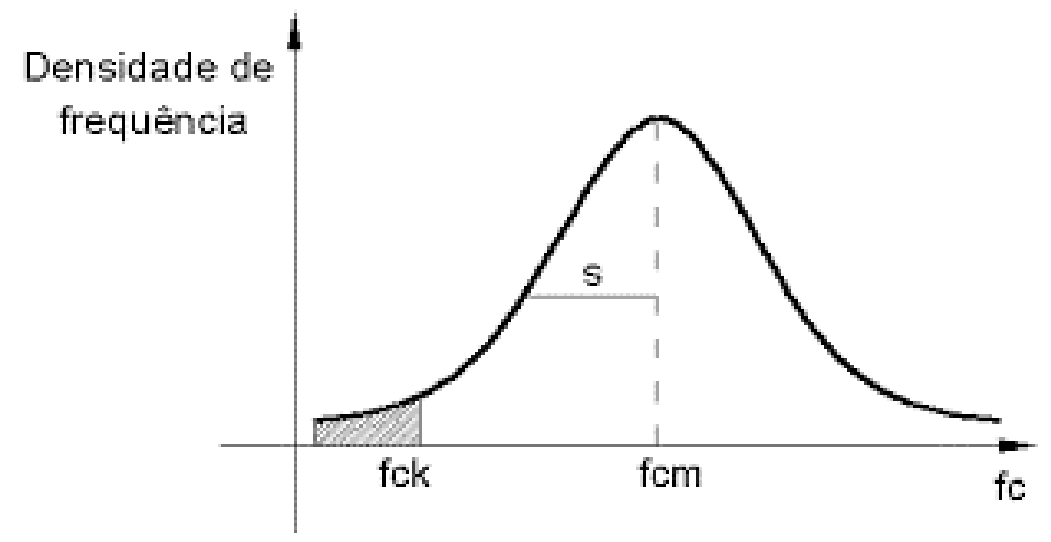

Fonte: LIBÂNIO (2007)

Diante do exposto no gráfico, dois valores são de grande importância, sendo eles a resistência média à compressão $F c m$, obtida através da média aritmética dos valores 
de resistência encontrados no ensaio, e a resistência característica à compressão do concreto Fck, cujo valor é dado pela fórmula (1):

Fck $=\mathrm{Fcm}-1,65 \mathrm{~s}$

Segundo Libânio (2007, p. 2.2), "o desvio-padrão $s$ corresponde à distância entre a abscissa de $\mathrm{Fcm}$ e a do ponto de inflexão da curva (ponto em que ela muda de concavidade), e o valor 1,65 corresponde ao quantil de $5 \%$, ou seja, apenas $5 \%$ dos corpos de prova possuem Fc $<$ Fck."

\subsection{CIMENTO PORTLAND}

O cimento Portland exerce o papel de ligante na composição do concreto. É resultado da mistura e moagem de compostos minerais inorgânicos calcinados que ao reagirem com a água tendem a formar uma pasta, que se torna sólida com o passar do tempo, capaz de unir-se em torno dos agregados do concreto (PEDROSO, 2009).

Na normativa brasileira ABNT NBR 12655 (2015) o cimento no item 3.1.22 é definido como sendo:

Aglomerante hidráulico obtido pela moagem de clínquer Portland, ao qual se adiciona, durante essa operação, a quantidade necessária de uma ou mais formas de sulfato de cálcio. Durante a moagem é permitido adicionar a essa mistura materiais pozolânicos, escórias granuladas de alto-forno e/ou materiais carbonáticos, nos teores indicados nas normas específicas. (NBR 12655, 2015).

Quando em contato com a água o cimento reage, quimicamente, resultando numa liberação exotérmica de calor, sendo associado a essa liberação de calor o termo calor de hidratação. A reação pode ser denominada hidrólise, e tende a variar com o tipo de cimento aplicado e o volume (NEVILLE, 2015).

Em peças ou elementos estruturais para Neville (2015) o calor total de hidratação não é de grande relevância, porém a velocidade com que a temperatura é dissipada é de 
grande importância, dado que quantidades elevadas de calor liberados em curto espaço de tempo podem ocasionar fissuração.

\subsubsection{HISTÓRICO DO CIMENTO}

O cimento é um material antigo, o seu uso é registrado no passado em construções de povos egípcios, gregos e romanos. A evolução veio com o surgimento de novos ares da arquitetura e engenharia na idade média (NEVILLE, 2015). Somente em 1824, Joseph Aspdin patenteou e propôs os primeiros modelos de controle científico para a fabricação do cimento Portland, recebendo esse nome em razão da semelhança de coloração com as pedras da ilha Inglesa de Portland. (VARELA; VIEIRA, 2009.)

Há relatos que a primeira fábrica de cimento do Brasil surgiu em meados do século XIX, no estado da Paraíba e, mais tarde, estendendo outras instalações no estado de São Paulo (SANTOS, 2011).

\subsubsection{PROCESSO DE FABRICAÇÃO DO CIMENTO}

Atualmente, há um conjunto de normativas que regem a produção de cimento e buscam, de modo simples, padronizar, em termos quantitativos, a dosagem dos minerais essenciais e adições necessárias aos tipos específicos de cimentos (NOGUEIRA, 2011).

Tendo em vista o processo de fabricação, Nogueira (2011) descreve os materiais primários da composição, sendo eles: gesso, argila e calcário. Após a extração, temse os seguintes processos: pré-homogeneização ou moagem, homogeneização, cozedura, resfriamento e as adições conforme o tipo a ser fabricado, podendo ser adicionado material carbonático, escórias e material pozolânico. A figura 2 ilustra o fluxo da fabricação do cimento. O produto final destes processos é o cimento, comumente conhecido e comercializado no mercado. 
Figura 2: Processo de fabricação do cimento

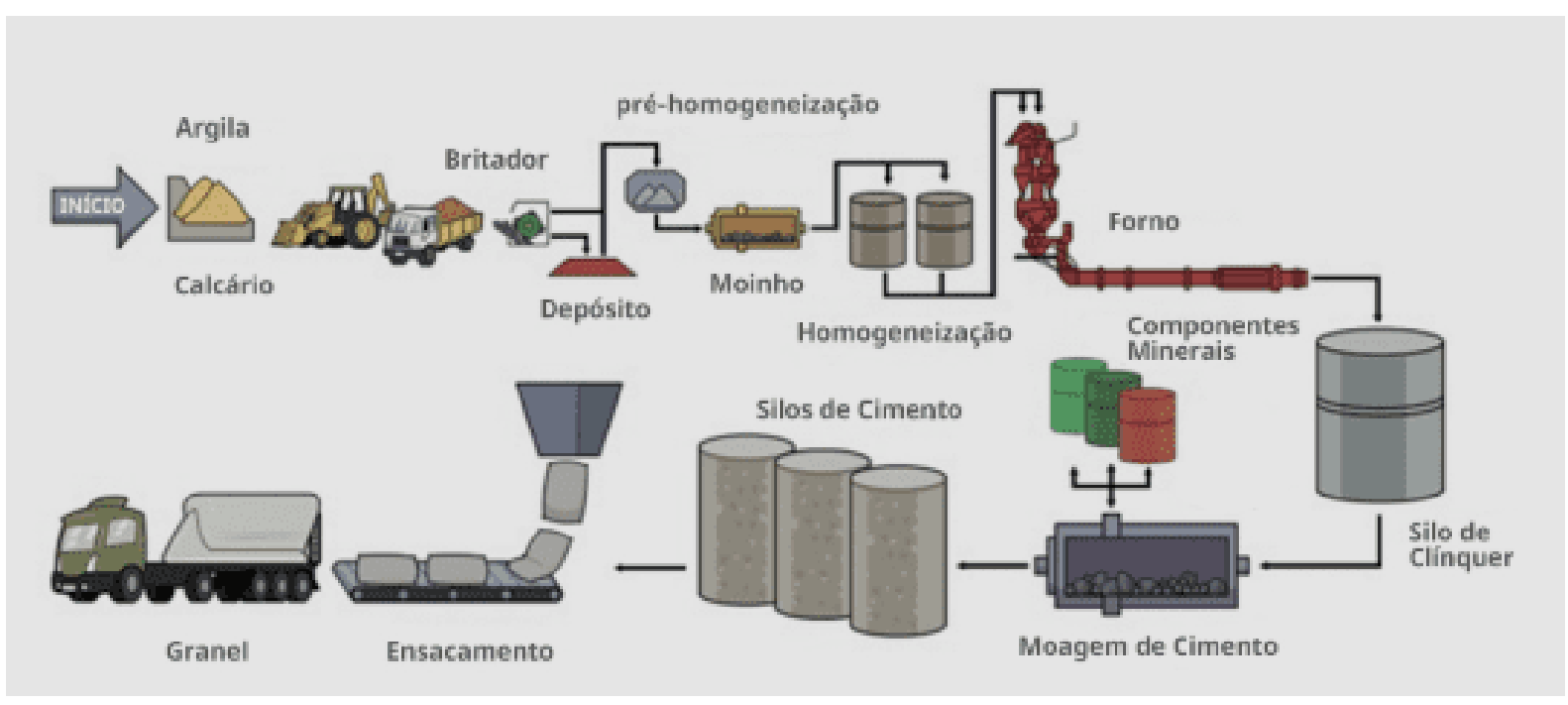

Fonte: Cimento Mauá (2017)

\subsubsection{TIPOS DE CIMENTOS}

Existem aproximadamente 11 tipos de cimento disponíveis no mercado (NBR 16697, 2018), cada um deles carrega sua especificidade a depender da adição mineral ou artificial que existe em sua composição, são eles:

\subsubsection{CIMENTO PORTLAND COMUM (CP I)}

A NBR 16697 (2018) diz que o cimento Portland comum se trata de:

Aglomerante hidráulico obtido pela moagem de clínquer Portland ao qual se adiciona, durante a operação, a quantidade necessária de uma ou mais formas de sulfato de cálcio. Durante a moagem é permitido adicionar a esta mistura materiais pozolânicos, escórias granuladas de alto-forno e/ou materiais carbonáticos.

Esse é o cimento mais usual, é ideal para construções onde não se possui perigo de exteriorizar sulfatos no solo ou em correntes subterrâneas, além de não conter adição de gesso (GALHARDO, 2014). 


\subsubsection{CIMENTO PORTLAND COM ADIÇÃO (CP I - S)}

Esse é um tipo de cimento Portland comum onde a sua massa é composta por $5 \%$ de material pozolânico, é ideal para construções de concreto onde há pouca decorrência de exteriorização de sulfatos no solo e em águas subterrâneas. $O$ cimento Portland com adição (CP I - S) é usado também caso não sejam necessárias propriedades especiais no cimento (NEVILLE, 2016).

\subsubsection{CIMENTO PORTLAND COMPOSTO COM ESCÓRIA GRANULADA DE ALTO FORNO (CP II - E)}

O cimento Portland CP II é composto por conta de conter a adição de um outro material além da sua composição básica (clínquer e gesso). É comumente usado em construções onde as estruturas precisam transmitir calor lentamente, pois o calor gerado pelo CP II é transmitido em uma velocidade menor do que pelo CP I. O CP II - E, em especial, abrange em sua massa a adição de 6 a 34\% de escória, podendo também obter até $10 \%$ de fíler (GALHARDO, 2014).

A NBR 16697 (2018) diz que a escória granulada de alto forno se trata de "um subproduto da produção do gusa, resultante do tratamento de minério de ferro em alto-forno, obtido sob forma granulada por resfriamento brusco, na forma vítrea, constituído em sua maior parte de silicatos e aluminosilicatos de cálcio."

\subsubsection{CIMENTO PORTLAND COMPOSTO COM ADIÇÃO DE MATERIAL POZOLÂNICO (CP II - Z)}

O cimento Portland CP II é uma composição intermediária entre o cimento Portland comum e os demais cimentos Portland com adições. O CPII-Z abrange em sua massa a adição de 6 a 14\% de pozolana, também pode obter até 10\% de fíler, permitindo ser usado nas construções e em especial, obras com presença de água por seu menor índice de permeabilidade (GALHARDO, 2014).

A NBR 16697 (2018) diz que materiais pozolânicos se trata de: 
Materiais silicosos ou sílico aluminosos, que por si sós possuem pouca ou nenhuma atividade hidráulica, mas que, quando finamente divididos e na presença de água, reagem com o hidróxido de cálcio, à temperatura ambiente, para formar compostos com propriedades cimentícias.

\subsubsection{CIMENTO PORTLAND COMPOSTO COM ADIÇÃO DE MATERIAL CARBONÁTICO FÍLER (CP II - F)}

O cimento Portland CP II é ideal para ser usado e aplicado em geral, mas preferencialmente em construções com contato de água por sua velocidade de transmitir o calor se torna menor. O CP II-F abrange em sua massa de 6 e 10\% de fíler calcário, não sendo uma boa opção para meios agressivos, é ideal para ser usado em construções em estruturas de concreto armado, assentamento de pisos, dentre outras (GALHARDO, 2014).

A NBR 16697 (2018) diz que materiais carbonáticos (fíler) se trata de "materiais finamente divididos, constituídos em sua maior parte de carbonato de cálcio."

\subsubsection{CIMENTO PORTLAND DE ALTO-FORNO COM ESCÓRIA (CP III)}

O cimento Portland alto-forno abrange em sua massa de 35 a $70 \%$ de adição de escória e até $5 \%$ de fíler. O CP III com escória é ideal para construções de grande porte e de grande índice de agressividade, além de estruturas de concreto em geral (GALHARDO, 2014).

A NBR 16697 (2018) diz que cimento Portland de alto-forno se trata de "cimento Portland obtido pela mistura homogênea de clínquer Portland e escória granulada de alto-forno, moídos em conjunto ou separadamente, podendo conter uma ou mais formas de sulfato de cálcio e materiais carbonáticos, nos teores estabelecidos nesta Norma." 


\subsubsection{CIMENTO PORTLAND COM POZOLÂNICO (CP IV)}

O cimento Portland pozolânico abrange em sua massa um alto índice entre 15 e 50\% de pozolana, o que favorece quando usado com agregados reativos. Os materiais pozolânicos e o clínquer são usados juntos. O CP IV é considerado o mais resistente entre os demais cimentos Portland, por conta de dispor de um nível de porosidade bem baixo e dessa forma é ideal para ser usado em construções de estrutura de alta complexidade (GALHARDO, 2014).

A NBR 16697 (2018) diz que cimento Portland pozolânico se trata de "cimento Portland obtido pela mistura homogênea de clínquer Portland e materiais pozolânicos, moídos em conjunto ou separadamente, podendo conter uma ou mais formas de sulfato de cálcio e materiais carbonáticos, nos teores estabelecidos nesta Norma."

\subsubsection{CIMENTO PORTLAND ALTO FORNO RESISTÊNCIA INICIAL (CP V - ARI)}

O cimento Portland de alta resistência inicial, CP V - ARI, não abrange adições em sua massa, mas pode obter até $5 \%$ de fíler. O CP V - ARI diferentemente dos demais tipos de cimento Portland alcança uma alta resistência logo após a sua aplicação e obtendo resistência até 28 dias que permite maior aproveitamento do concreto. É ideal para construções de estruturas que necessitam de desforma rápida (GALHARDO, 2014).

A NBR 16697 (2018) diz que cimento Portland de alta resistência inicial se trata de "cimento Portland que atende aos requisitos de alta resistência inicial."

\subsubsection{CIMENTO PORTLAND DE BAIXO CALOR DE HIDRATAÇÃO (CP - BC)}

O cimento Portland de baixo calor de hidratação, CP - BC surgiu nos Estados Unidos para combater o problema de superaquecimento gerado pelos concretos fabricados com os cimentos convencionais em obras de barragem verticais. $O$ calor proveniente 
da cura do concreto, além de gerar fissuras e trincas nos elementos, impedia o trabalho dos colaboradores (SOBRAL, 2000).

No Brasil, a fabricação deste cimento é regulamentada, também, pela NBR 16697 (2018) que preconiza os critérios para o CP - BC como a capacidade de manter durante 41 horas temperaturas inferiores a $270 \mathrm{J.g}^{-1}$.

A NBR 16697 (2018) diz que cimento Portland de baixo calor de hidratação se trata de "cimento Portland que atende à condição de baixa liberação de calor durante a sua hidratação, de acordo com os limites estabelecidos nesta norma."

\subsubsection{CIMENTO PORTLAND BRANCO (CP - B)}

O cimento Portland branco difere dos demais tipos de cimento devido a sua coloração, que é resultado da matéria-prima e da sua fabricação. O cimento Portland branco é dividido em dois tipos: o estrutural e o não estrutural, onde o não estrutural é utilizado para fins arquitetônicos não estruturais e para rejuntamento de cerâmicas (GALHARDO, 2014).

A NBR 16697 (2018) diz que cimento Portland branco se trata de "cimento Portland constituído de clínquer Portland branco e cujas adições (sulfato de cálcio ou outras) não geram alterações em sua coloração além dos limites estabelecidos nesta Norma."

\subsubsection{CIMENTO PORTLAND RESISTENTE A SULFATOS (CP - RS)}

O cimento Portland resistente a sulfatos tem a função de proporcionar resistência aos ambientes agressivos sulfatados. É ideal para ser usado em construções de obras de recuperação estrutural, concretos, dentre outras (GALHARDO, 2014).

A NBR 16697 (2018) diz que sulfato de cálcio se trata de "material de origem natural ou industrial encontrado sob as formas de gipsita ( $\mathrm{CaSO} 4.2 \mathrm{H} 2 \mathrm{O})$, hemidrato ou bassanita ( $\mathrm{CaSO} 4.1 / 2 \mathrm{H} 2 \mathrm{O})$, anidrita (CaSO4) ou mistura das várias formas, adicionado ao cimento com o objetivo de regular a pega." 


\subsection{AGREGADOS}

Os agregados, materiais presentes no concreto, inertes, os quais não possuem volume e nem forma definida, são escolhidos com base em especificações técnicas e classificados conforme a ABNT NBR 7211 (2005) por meio de ensaios de peneiramento que obedecem a ABNT NBR NM 248 (2003).

Os agregados miúdos e graúdos são segundo a ABNT NBR 7211 (2005) são classificados e definidos como sendo:

Agregados miúdos: Agregado cujos grãos passam pela peneira com abertura de malha de $4,75 \mathrm{~mm}$ e ficam retidos na peneira com abertura de malha de $150 \mu \mathrm{m}$, em ensaio realizado de acordo com a ABNT NBR NM 248, com peneiras definidas pela ABNT NBR NM ISO 3310-1. (NBR $7211,2005)$.

Agregados graúdos: Agregado cujos grãos passam pela peneira com abertura de malha de $75 \mathrm{~mm}$ e ficam retidos na peneira com abertura de malha de $4,75 \mathrm{~mm}$, em ensaio realizado de acordo com a ABNT NBR NM 248, com peneiras definidas pela ABNT NBR NM ISO 3310-1. (NBR $7211,2005)$.

\subsection{DOSAGEM DO CONCRETO}

A dosagem do concreto, também conhecida como traço, é a fase onde a quantidade de materiais é dosada entre si, a fim de obter-se a melhor proporção, para atender às questões econômicas, disponibilidade materiais constituintes e as solicitações especificadas. A mistura ideal busca atender especificações técnicas solicitadas em conformidade com a execução e resistência final (NEVILLE, 2015).

Segundo Pinheiro (2010), Fck é a resistência característica do concreto à compressão, valor esse que tem a probabilidade de $95 \%$ de ser alcançado através do ensaio de compressão axial para cada lote de concreto. 
Outras propriedades também podem ser levadas em consideração, tais como a trabalhabilidade, tangendo ao transporte, lançamento e bombeamento, taxa de armadura existente, onde a acomodação deve ser realizada sem segregação (HELENE; ANDRADE, 2011). A durabilidade e deformabilidade também são parâmetros consideráveis, uma vez que são previstas perdas e são realizadas compensações.

A sustentabilidade na produção de concreto pode ser introduzida em termos de se fazer mais com menos, aplicando concreto de maiores resistências, reduzindo seções a serem concretadas há a redução de matéria prima utilizada (TUTIKIAN; HELENE, 2011).

\subsection{ENSAIO DE COMPRESSÃO}

O ensaio de compressão em corpos de prova cilíndricos é normatizado pela ABNT NBR 5739 (2018), que objetiva medir a evolução do ganho de resistência em idades pré-determinadas, é um indicador das características também dos materiais constituintes do concreto, uma vez que materiais mal dosados ou de baixa qualidade influem diretamente no ganho de resistência.

Quando são realizadas concretagens de peças estruturais, sendo elas pilares, vigas ou lajes, é recomendado o mapeamento do processo de lançamento do concreto e que sejam elaborados corpos de provas para cada caminhão, a finalidade é correlacionar com os resultados obtidos em laboratório dos corpos de prova moldados em obra com aqueles que são requeridos em projeto. Essa análise é realizada através do ensaio de compressão, a partir dos resultados, caso haja discrepância, é sabido o local onde deverá ocorrer a avaliação e possivelmente reforços, cabendo ao responsável técnico ou ao estruturalista decidir a viabilidade (CIOTTA e JUNIOR, 2018). 


\section{ESTADO DA ARTE}

A constante preocupação com a qualidade dos insumos, usados na confecção de elementos estruturais, tem motivado a comunidade de engenheiros a averiguar, selecionar e testar os mais variados tipos de cimentos disponíveis (GOBBO, 2009)

Apesar de todos os cimentos distribuídos no mercado brasileiro necessitarem de aprovação em um criterioso teste de qualidade imposto pelas normativas técnicas pertinentes, tais como a NBR 16697 (2018), para que somente assim possam ser disponibilizados, inúmeras são as variáveis que podem afetar as propriedades do cimento Portland e, em consequência, as propriedades dos materiais oriundos do mesmo, como o concreto.

Preocupados com o desempenho dos cimentos Portland, diversos estudos (NÓBREGA e SILVA, 2012; PADILHA, PALIGA e TORRE, 2017; PEREIRA, 2012; MEDEIROS, 2014; NOBRE, 2003) têm sido publicados buscando comparar parâmetros como resistência do concreto à compressão, trabalhabilidade, dentre outros, utilizando concretos fabricados com cimentos de diferentes tipos, por meio de ensaios como o de compressão axial.

\subsection{ESTUDO COMPARATIVO DAS MARCAS DE CIMENTO PORTLAND EMPREGADAS NA PRODUÇÃO DE CONCRETO NO ESTADO DO RIO GRANDE DO NORTE}

O primeiro estudo analisado foi publicado por Ana Cecília Vieira da Nóbrega e Djalma Ribeiro da Silva pela UFRN para o Departamento de Química e tem como objetivo o estudo comparativo das marcas de cimento Portland empregadas na produção de concreto no estado do Rio Grande do Norte (NÓBREGA; SILVA, 2012).

Os autores, por se tratarem de profissionais da área química, iniciam sua metodologia não apenas estabelecendo os critérios utilizados para a determinação de um traço, mas também descrevendo as diferentes marcas de cimento por sua composição 
química. Não houve, entretanto, cuidado dos autores em especificar os processos necessários para esta descrição.

Para fins do trabalho acima citado, foi elaborado mais de um traço para cada uma das três marcas de cimento ( $A, B$ e $C$ ), cada um deles foi submetido a ação de dois diferentes aditivos sendo o primeiro deles $0,5 \%$ de superplastificante, e o segundo a mistura de $0,5 \%$ de superplastificante e $6 \%$ de fumo de sílica. Foram ainda utilizados traços com diferentes proporções de água e cimento, sendo eles $0,55,0,5$ e 0,45.

Os cimentos apresentaram desempenhos significantemente distintos, ainda que respeitando as mesmas proporções para os traços. A adição de aditivos, ainda, provocou alterações na trabalhabilidade, resistência e absorção de água diferente para cada uma das marcas analisadas no estudo, algumas delas não atingiram sequer o mínimo de trabalhabilidade e de resistência necessária, em alguns dos cenários propostos.

O estudo conclui, apesar de não pontuar como ou o porquê, que a estrutura química dos cimentos analisados influi diretamente na resistência e trabalhabilidade do concreto. A autora ainda expressa que há uma direta relação entre o fator água cimento, sendo essa relação inversamente proporcional, e a resistência, onde concretos com menor a/c obtiveram maior resistência axial à compressão. Maiores resistências ainda puderam ser percebidas em total nas misturas que tiveram a adição do aditivo fumo de sílica.

\subsection{ESTUDO COMPARATIVO DA RESISTÊNCIA À COMPRESSÃO DE BLOCOS DE CONCRETO PRODUZIDOS COM DIFERENTES CIMENTOS E DOSADOS EM AMBIENTE DE FÁBRICA}

Também preocupados em como as diferentes marcas de cimento podem interferir na qualidade do concreto produzido Stael Amaral Padilha, Charlei Marcelo Paliga e Ariela da Silva Torre publicaram um estudo que buscou comparar a resistência à compressão de blocos de concreto produzidos com diferentes cimentos e dosados em ambiente de fábrica (PADILHA; PALIGA; TORRE, 2017). 
O estudo de Padilha, Paliga e Torre (apud FRASSON JUNIOR, 2000) propõe a analisar a dosagem para concreto seco proposta por comparando três tipos de cimento, e três combinações de traço. Os cimentos Portland utilizados para o estudo foram CP II - F 32, CP IV 32 e CP V - ARI. Para a dosagem a relação cimento/agregado utilizada foi $1: 6 ; 1: 8 ; 1: 10$. Foram geradas então 9 famílias de blocos, cada uma delas referente a uma traço específico realizado com um determinado tipo de cimento, obedecendo os parâmetros de fabricação rompimento e ensaios estabelecidos pelas normas NBR 6136 (2014) e NBR 12118 (2011).

Os resultados obtidos são analisados conforme as dosagens usadas para a produção do bloco, bem como o comparativo entre os cimentos utilizados. Ao contrário do que a intuição possa levar a concluir, os maiores valores para a resistência aos 28 dias não foram obtidos pelo cimento de alta resistência inicial, apesar de ele ter alcançado o maior valor de resistência absoluta quando dosado para o traço de 1:6, foi o CP IV que obteve os maiores valores para as demais dosagens.

Por fim, o artigo encerra suas considerações comparando as resistências obtidas com o seu custo benefício, apesar de haver maior resistência nas famílias produzidas com traço 1:6, há também o maior consumo de cimento o que encarece a produção, sendo assim o mais viável seriam os blocos fabricados com 1:8 que possuem melhor resistência para o menor consumo de cimento.

\subsection{ESTUDO SOBRE OS TIPOS DE CIMENTO COMERCIALIZADOS EM CAMPO MOURÃO}

No trabalho de Pereira (2012), é proposto um estudo relativo à análise qualitativa através de ensaios normatizados de cimentos comumente encontrados no município de Campos do Mourão. A priori é descrito a história do cimento, seu surgimento e utilização pelo mundo e suas primeiras aplicações no Brasil em consolidação de pequenas, médias e grandes obras de engenharia.

$\mathrm{Na}$ sequência, é discorrido sobre os tipos de cimentos, sendo relatados os 11 tipos disponíveis no mercado e suas respectivas recomendações e indicações de uso para 
cada tipo de construção e ou peça estrutural em específico. As adições são mencionadas de forma direta ao entendimento, apontando a influência de cada uma nas reações químicas e na resistência da mistura final, podendo ser argamassa ou concreto. As normativas técnicas são constantemente citadas como ponto de partida para a elaboração e composição do material em fábricas.

Metodologicamente foram realizados alguns ensaios, sendo eles de peneiramento, de análise do tempo de pega e de compressão axial. Inicialmente, foram prédeterminadas 4 marcas de cimento e escolhido o tipo CP II. Em seguida, o ensaio de peneiramento foi executado de modo a determinar o módulo de finura, em seguida foi preparada uma pasta de cimento e areia para a composição dos ensaios de tempo de pega e resistência à compressão, sendo que todos os ensaios acompanharam as prescrições normativas cabíveis.

De forma a fazer jus à pesquisa os dados foram analisados e cruzados de forma a avaliar se um parâmetro influencia diretamente em outro. Em determinado momento, foi verificada a influência do módulo de finura na resistência inicial e final, logo os cimentos que se apresentaram mais finos apresentaram uma resistência inicial um pouco maior na primeira idade, e ao final dos 28 dias uma resistência um pouco menor que os demais. Foi verificado também que há interação entre tempo de pega, a finura do cimento e a liberação de calor, uma vez que quanto mais fino o cimento maior é, em módulo, o coeficiente de liberação de calor.

A variação de temperatura da região durante a realização da pesquisa foi relacionada ao ganho de resistência na idade de 28 dias. É também observado que a realização do ensaio envolvendo corpos de prova de concreto seria interessante, pois, sendo este o material construtivo mais utilizado atualmente, reduzir-se-ia a distância entre realidade e experimentação científica laboral. 


\subsection{INVESTIGAÇÃO DA RESISTÊNCIA À COMPRESSÃO E DA RESISTIVIDADE ELÉTRICA DE CONCRETOS COM DIFERENTES TIPOS DE CIMENTO}

De forma relevante, Medeiros Junior (2014) aborda a resistência à compressão e controle da consistência de forma indispensável para a engenharia. O ensaio de compressão axial é dito como essencial aliado a isso se faz presente a resistividade elétrica, que é uma característica do concreto diretamente relacionado à permeabilidade e à resistência que o concreto tem à penetração de agentes químicos agressivos como os dióxidos e cloretos. Ao contrário do ensaio de compressão, onde são rompidos corpos de prova, a resistividade pode ser verificada por meio de ensaios não destrutivos.

O experimento foi composto por quatro tipos de cimento, com adições variando entre materiais pozolânicos, clínquer, escórias, dentre outras. Foi moldada uma determinada quantidade de corpos de provas, tanto para o ensaio de resistência quanto para o ensaio de resistividade elétrica. Os traços desses corpos de prova possuem a mesma dosagem, variando apenas a relação água cimento, como forma de averiguar a influência nos dois parâmetros. Os procedimentos seguiram as normativas vigentes como forma de nortear e ponderar as ações executadas.

Os dados obtidos foram dispostos de forma textual, em gráficos de linhas com a disposição da relação força aplicada versus tempo e o gráfico de barras para a resistividade elétrica, salientando a divisão para cada tipo de cimento. A correlação da resistência à compressão com a resistividade elétrica é analisada também graficamente, associando as idades e a relação água/cimento.

De forma a concluir o raciocínio, o autor traz breves conclusões com relação ao ganho de resistência inicial e final com referência ao tipo de cimento em questão e ressalta que a resistividade aumenta onde a relação água/cimento diminui e aumenta logaritmicamente à medida que a idade avança. 


\subsection{AVALIAÇÃO DAS CARACTERÍSTICAS MECÂNICAS E DA DURABILIDADE AO ATAQUE QUÍMICO DE DIFERENTES TIPOS DE CONCRETO DE CIMENTO PORTLAND}

O trabalho de Nobre (2003) se inicia com uma menção aos agentes químicos que causam degradações nas estruturas de concreto. Na sequência, são tratados alguns tipos de ácidos apontados como de comum ou recorrente contato com concreto, desse modo foi ressaltada a importância do estudo envolvendo reações químicas relacionadas com os parâmetros da relação água cimento e a resistência à compressão com variação do tipo de cimento.

Para o desenvolvimento experimental, nota-se a escolha de alguns materiais relevantes, sendo eles os tipos de cimento, os agregados, as relações de dosagem, o abatimento previsto e os métodos utilizados na dosagem. Posteriormente, foram moldados corpos de prova cilíndricos em obediência a norma NBR 5738 (2015) e corpos de prova prismáticos. Os corpos cilíndricos foram submetidos ao processo de cura para o rompimento na prensa em idades pré-estabelecidas, enquanto os corpos de prova prismáticos foram submetidos a processos de exposição a ácidos e processo de pesagem periódica. As pesagens verificaram a perda de massa dentro de um ciclo de 5 a 6 dias.

Os resultados referentes à resistência apresentaram que o cimento CP V obteve valores superiores ao CP IV, e é justificado por sua adição e característica de granulometria mais fina, e, consequentemente, apresentou-se com taxas de hidratações maiores, o que levou a sua maior resistência à compressão.

Os métodos de dosagem são confrontados e o método citado como IPT/EPUSP (HELENE; TERZIAN, 1993) apresentou resultados significativamente superior em todas as idades em relação ao método descrito como ABCP/ACI (RODRIGUES, 1995), que é citado pelo autor como semi-experimental, uma vez que não contempla a realidade da qualidade dos materiais. 
Para os corpos de prova prismáticos expostos aos ácidos, o parâmetro da relação água/cimento se demonstrou diretamente ligado à perda de massa e à degradação que ocorreu. Quanto maior foi a relação a/c maior perda de massa, maior permeabilidade e, consequentemente, maior o fluxo do agente químico agressivo.

Conclusões são apresentadas em relação ao tipo de cimento, que está diretamente ligado a resistência, ressaltando que cimentos com adições pozolânicas são menos resistentes por seu elevado teor de sílica. Para a degradação e ataque químico, os concretos com baixa relação a/c perdem menos massa. No processo de aceleração de degradação, o ácido lático se destacou como mais reativo na perda de massa em relação aos ácidos clorídricos e acéticos e o método IPT/EPUSP (HELENE; TERZIAN, 1993) se mostrou mais resistente ao ataque de agentes químicos.

\section{CONSIDERAÇÕES FINAIS E DIRECIONAMENTOS FUTUROS}

Por meio desse trabalho, foi possível perceber, além de aspectos básicos como a importância do concreto como material de construção, a importância do conhecimento das suas propriedades e dos materiais que o compõem. Foi visto que o cimento mistura pulverulenta que é responsável por ser o aglomerante hidráulico, ou seja, o ligante do concreto, apresenta características variadas a depender do tipo, das adições e do processo de fabricação, o que tem relação direta com o concreto que se é obtido.

Através da realização desta pesquisa, foi possível perceber que há no meio acadêmico uma variedade de trabalhos que tratam do tema abordado de forma interessante, os quais tornaram visível que existe sim uma variação, a depender do tipo de cimento e da adição utilizada, de determinados parâmetros quando submetese o concreto ou a argamassa de cimento à configurações especiais de ensaios e condições. Partindo disso, este trabalho sugere ainda a realização de ensaios em laboratório, os quais, além de analisar o comportamento e a relação de certos parâmetros em função do tipo de cimento, levem em consideração a variação de marcas para um mesmo tipo, visto que, devido ao controle de qualidade e a 
possibilidade de variação, é possível que existam diferenças relevantes nos seus resultados.

\section{REFERÊNCIAS}

ASSOCIAÇÃO BRASILEIRA DE NORMAS TÉCNICAS. NBR NM 248: Agregados Determinação da composição granulométrica. Rio de Janeiro, 2003.

ASSOCIAÇÃO BRASILEIRA DE NORMAS TÉCNICAS. NBR 11579: Cimento Portland-Determinação do índice de finura por meio da peneira 75 m (nํ200). 2012.

ASSOCIAÇÃO BRASILEIRA DE NORMAS TÉCNICAS. NBR 12655: Concreto de cimento Portland - Preparo, controle, recebimento e aceitação-Procedimento. Rio de Janeiro, 2015.

ASSOCIAÇÃO BRASILEIRA DE NORMAS TÉCNICAS. NBR 15146: Controle tecnológico de Concreto-Qualificação de pessoal-Requisitos. Rio de Janeiro, 2004.

ASSOCIAÇÃO BRASILEIRA DE NORMAS TÉCNICAS. NBR 16697: Cimento Portland-Requisitos. Rio de Janeiro, 2018.

ASSOCIAÇÃO BRASILEIRA DE NORMAS TÉCNICAS. NBR 5738: ConcretoProcedimento para moldagem e cura de corpos de prova. Rio de Janeiro, 2015.

ASSOCIAÇÃO BRASILEIRA DE NORMAS TÉCNICAS. NBR 7211: Agregados para Concreto-Especificação. Rio de Janeiro, 2005.

ASSOCIAÇÃO BRASILEIRA DE NORMAS TÉCNICAS. NBR 9479: Argamassa e concreto- Câmaras úmidas e tanques para cura de corpos-de-prova. Rio de Janeiro, 2006.

ASSOCIAÇÃO BRASILEIRA DE NORMAS TÉCNICAS. NBR 5739: Concreto: ensaio de compressão de corpos-de-prova cilíndricos. Rio de Janeiro, 2018. 
BATTAGIN, Arnaldo Forti. Uma breve história do cimento Portland. Associação Brasileira de Cimento Portland. São Paulo. Disponível em <www. abcp. com. br [15/07/2003], 2009.>

CIOTTA, Pablo Henrique; JUNIOR, Francisco Roberto da Silva Machado. A importância do controle de qualidade e rastreabilidade do concreto armado usinado in loco. Revista Tecnológica / ISSN 2358-9221, [S.I.], v. 7, n. 1, p. 1 - 18, may 2018. ISSN 2358-9221.

Como é feito o cimento, sua composição e nomenclatura no mercado. Cimento Mauá, 2017. Disponível em: <https://cimentomaua.com.br/blog/cimento-como-feitocomposicao-e-nomenclatura/>. Acesso em: mar. 2020.

EVANGELISTA, Ana Catarina Jorge. Avaliação da resistência do concreto usando diferentes ensaios não destrutivos. Rio de Janeiro, 2002.

GALHARDO, Pedro Gutierrez. Estudo da produção de cimento com ênfase no classe g. 2014. Tese de Doutorado. Universidade Federal do Rio de Janeiro.

GOBBO, Luciano de Andrade. Aplicação da difração de raios-X e método de Rietveld no estudo de cimento Portland. 2009. Tese de Doutorado. Universidade de São Paulo.

HELENE, Paulo; ANDRADE, Tibério. Concreto de cimento Portland. Isaia, Geraldo Cechella. Materiais de Construção Civil e Princípios de Ciência e Engenharia de Materiais. São Paulo: IBRACON, v. 2, p. 905-944, 2007.

MEDEIROS-JUNIOR, R. A. et al. Investigação da resistência à compressão e da resistividade elétrica de concretos com diferentes tipos de cimento. Revista Alconpat, v. 4, n. 2, p. 116-132, 2014.

NEVILLE, Adam M. Propriedades do Concreto - 5ª Edição. Bookman Editora, 2015. 
NOBRE, Thiago Ricardo Santos et al. Avaliação das características mecânicas e da durabilidade ao ataque químico de diferentes tipos de concreto de cimento Portland. Revista de Iniciação Científica da ULBRA, n. 2, 2003.

NÓBREGA, et al. Estudo comparativo das marcas de cimento Portland empregadas na produção de concreto no estado do Rio Grande do Norte. Natal, RN, 2012.

NOGUEIRA, Jacqueline Andrade. Análise da Produção de Cimento Portland. 2011

PADILHA, Stael Amaral; PALIGA, Charlei Marcelo; TORRES, Ariela Silva. Estudo Comparativo da Resistência à Compressão de Blocos de Concreto Produzidos com Diferentes Cimentos e Dosados em Ambiente de Fábrica. REEC-Revista Eletrônica de Engenharia Civil, v. 13, n. 2, 2017.

PEDROSO, Fábio Luís. Concreto: as origens e a evolução do material construtivo mais usado pelo homem. Concreto e construções, v. 53, p. 14-19, 2009.

PEREIRA, Miguel Fernandes. Estudo sobre os tipos de cimento comercializados em Campo Mourão. 2012. Trabalho de Conclusão de Curso. Universidade Tecnológica Federal do Paraná.

PINHEIRO, Libânio M. et al. Estruturas de concreto - capítulo 2. São Paulo, 2010.

PINHEIRO, Libânio M. Fundamentos do concreto e projeto de edifícios. 2007.

SANTOS, Leandro Bruno. A indústria de cimento no Brasil: origens, consolidação e internacionalização. Sociedade \& Natureza, v. 23, n. 1, p. 77-94, 2011.

SOBRAL, Hernani Sávio. Propriedades do concreto fresco. São Paulo: ABCP, 2000.

TUTIKIAN, Bernardo F.; HELENE, Paulo. Dosagem dos concretos de cimento Portland. 2011. 
Tipos de Cimentos Portland. Disponível em: <https://https://cimento.org/tipos-decimento-2/>. Acesso em: mar. de 2020.

VARELA, Noel; VIEIRA, Fernando Sales. Cimento: Uma matéria-prima essencial no fabrico de argamassas. In: $1^{0}$ Congresso Nacional de Argamassas de Construção, APFAC, Lisboa. 2005.

VIEIRA, José Orlando Filho. Avaliação da Resistência à Compressão do Concreto através de Testemunhos Extraídos: Contribuição à Estimativa do Coeficiente de Correção devido aos Efeitos do Broqueamento. São Paulo, Universidade de São Paulo, Escola Politécnica, Programa de Pós Graduação em Engenharia Civil, Departamento de Engenharia de Construção Civil, 2007. Universidade de São Paulo, 2007.

Enviado: Abril, 2020.

Aprovado: Maio, 2020. 